\title{
PREFACE
}

\section{Career Development}

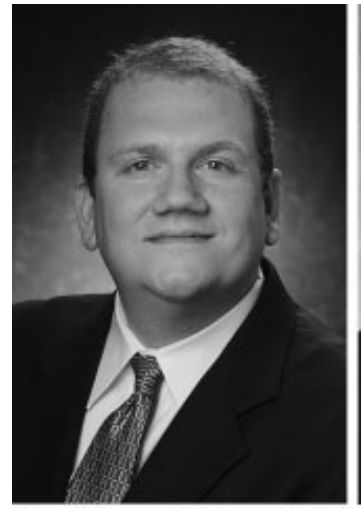

H.T.Papaconstantinou, M.D.

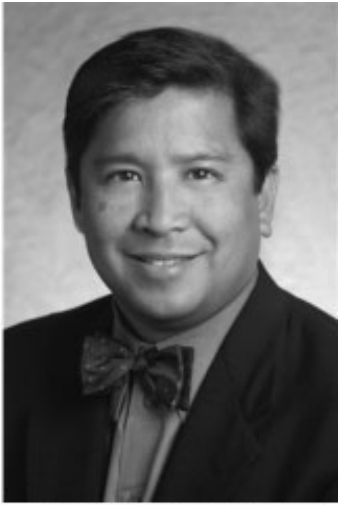

H. David Vargas, M.D.
Training in general surgery and colon and rectal surgery prepares us for the treatment and management of our patients. Unfortunately, few residency programs prepare their trainees for the next step... getting a job. There are few written resources available, and most of us rely on our mentors and friends for advice and guidance. The same is true for our colleagues who have chosen to redefine their career (e.g., academics to private practice or military practice to academics). This issue of Clinics in Colon and Rectal Surgery is devoted to career development, with a goal to provide the reader with defined career options in colon and rectal surgery and basic information to help develop a successful and satisfying career.

A colon and rectal surgery career starts with an approved training program (colon and rectal surgery residency or "fellowship"). A current trainee describes his experience and offers advise for future applicants to our specialty. After training, there are various career opportunities for colon and rectal surgeons in private practice, clinic practice, the military, and academics. The next few articles define these career paths and give insight into the risks and benefits of each. When considering job opportunities, we feel these articles will give the reader a broad overview of immediate and long-term considerations to facilitate an informed career decision.
Within academic surgery, there are many career opportunities for colon and rectal surgeons. The different academic tracks offered at most university medical centers include clinical surgeon, clinical scholar, surgical educator, and surgical scientist. Each of these career tracks has specific job expectations and requirements for advancement. In this issue we explore and define these different career tracks and provide basic information about the process and meaning of promotion and tenure. Specific articles on research in academics and education provide additional tools and advise on how to optimize your efforts into a successful academic career.

When considering job opportunities, a fundamental knowledge of contracts and contract contents helps the applicant understand the terms of hire. Specific items to consider are qualifications, remuneration, hidden costs, restrictive covenants, and even termination of contract. Signing a contract means that you understand and agree with its contents and terms, and it is a legally binding document. We recommend that all applicants have contracts reviewed by a qualified attorney to ensure that the best possible circumstances exist to ensure a successful transition and career in your new job.

Developing a colon and rectal surgery practice is as much a business as it is patient care. As physicians, we control a significant component of health care costs, and
${ }^{1}$ Section of Colon and Rectal Surgery, ${ }^{2}$ Division of Surgical Oncology, Department of Surgery, The Texas A\&M University System Health Science Center, Scott and White Hospital, Temple, Texas; ${ }^{3}$ Tidewater Surgical Specialists, PLLC, Chesapeake, Virginia.

Address for correspondence and reprint requests: Harry T. Papaconstantinou, M.D., Section of Colon and Rectal Surgery, Division of Surgical Oncology, Department of Surgery, The Texas A\&M University System Health Science Center, Scott and White Hospital,
2401 South 31st St., Temple, TX 76508. E-mail: hpapaconstantinou@ swmail.sw.org.

Career Development; Guest Editors, Harry T. Papaconstantinou, M.D., H. David Vargas, M.D.

Clin Colon Rectal Surg 2006;19:105-106. Copyright (C) 2006 by Thieme Medical Publishers, Inc., 333 Seventh Avenue, New York, NY 10001, USA. Tel: +1(212) 584-4662.

DOI 10.1055/s-2006-948018. ISSN 1531-0043. 
this affects our bottom line through practice expense and margin. Improving reimbursement includes correct and efficient coding and billing. Furthermore, concepts of practice assessment and modeling are provided to help optimize efficiency and increase productivity. These concepts are necessary to develop a financially successful practice.

Retirement is something we are all aware of, but for most young colon and rectal surgeons it is limited to financial considerations. This is somewhat narrow minded and does not take into consideration personal factors that we may not consider early in our careers. Retirement is a personal and individual event. The questions of when, why, and how is more individual specific and is shaped by our life experience, desires, personal and family commitments, and financial considerations. In this issue we have asked some respected members of our profession to share with us their experiences with retirement.

We are grateful to our colleagues who have contributed to this issue. These topics are not readily found or reviewed elsewhere in the literature, and therefore you will not find many references used in these articles. This has presented significant challenges for the authors; however, by including their successful experiences and knowledge gained through navigating career choices and challenges, these articles are paving a trail to provide our upcoming colleagues with the information and basic tools to achieve a successful and rewarding career in colon and rectal surgery.

Harry T. Papaconstantinou, M.D. H. David Vargas, M.D. Guest Editors ${ }^{1,2,3}$ 